\title{
Genetic control of the rate of wound healing in mice
}

\author{
XINMIN LI†, WEIKUAN GU $\dagger$, GODFRED MASINDE $\uparrow$, MELANIE HAMILTON- \\ ULLAND $\uparrow$, SHIZHONG XU†, SUBBURAMAN MOHAN $\uparrow \&$ DAVID J. BAYLINK*† \\ $\uparrow$ Molecular Genetics Division, Musculoskeletal Disease Center, JL Pettis VA Medical Center and Loma Linda \\ University, Loma Linda, CA 92357, U.S.A. and $\ddagger$ Department of Botany and Plant Sciences, \\ University of California, Riverside, CA 92521-0124, U.S.A.
}

\begin{abstract}
There have been few studies of the inheritance of wound healing in mammals. In this study, we demonstrate that inbred strains of mice differ significantly in the rate of wound healing. Of the 20 strains tested, fast healers (MRL/MpJ-Fas ${ }^{\mathrm{lpr}}$ and $\mathrm{LG} / \mathrm{J}$ ) healed wounds four times faster than slow healers $(\mathrm{Balb} / \mathrm{cByJ}$ and $\mathrm{SJL} / \mathrm{J})$. The genetic basis underlying the difference in the healing capacity was analysed using $F_{2}$ populations of two different crosses. We show that the wound healing is a polygenically determined quantitative trait with an average estimated heritability of $86 \%$. The modes of gene action in these two crosses are different. In the $(\mathrm{MRL} / \mathrm{MpJ} \times \mathrm{SJL} / \mathrm{J})$ cross, genes regulating fast healing in MRL/MpJ mice exhibited additive effects, whereas these effects were suppressed by a dominant repressor gene in $\mathrm{CBA} / \mathrm{J}$ mice in the $\left(\mathrm{MRL} / \mathrm{MpJ}-\mathrm{Fas}^{\mathrm{lpr}} \times \mathrm{CBA} / \mathrm{J}\right)$ cross. Information gained from this investigation provides insight into further study of molecular mechanisms underlying the rate of wound healing in mammals.
\end{abstract}

Keywords: genetic variability, heritability, inbred mouse, quantitative trait, segregating population, wound healing.

\section{Introduction}

Wound healing is a complex process requiring the joint effort of many different genes (Kunimoto, 1999). The clinical endpoints of mammalian wound repair involve the quality of healing (tissue regeneration) and the rate of healing (Goss, 1992; Martin, 1997; Singer \& Clark, 1999). In vivo animal models have been developed to study the mechanisms of wound healing in both normal and impaired states (Rothe \& Falanga, 1992). Studies have shown that topological application of cod liver oil ointment, vitamin A, deoxyribonucleosides, and some proteins can accelerate wound healing (Shah et al., 1995; Chen et al., 1999; Terkelsen et al., 2000). However, up to now we know very little about the inheritance of the rate of wound healing and the mode of its inheritance.

In 1998, Clark et al. accidentally found that the MRL/MpJ-Fas ${ }^{\text {lpr }}$ (MRL-F) strain of mice could completely heal an ear-punched hole (2 $\mathrm{mm}$ in diameter) with normal tissue architecture within 4 weeks in contrast to the control mice, C57BL/6J (B6), which

*Correspondence. Musculoskeletal Disease Center, JL Pettis VA Medical Center, 11201 Benton Street (151), Loma Linda, CA 92357, U.S.A. E-mail: baylid@lom.med.va.gov only healed $30 \%$ of the original hole with scar tissue at the same period of time (Clark et al., 1998). Using $(\mathrm{MRL}-\mathrm{F} \times \mathrm{B} 6) \mathrm{F}_{2}$ and backcross populations, it was demonstrated for the first time that rapid wound healing in MRL-F mice is a genetically controlled quantitative trait (McBrearty et al., 1998). This study led to an opportunity to search for fast-healer genes in mammals and also raised several fundamental questions related to genetic variability and heritability of wound healing that will be addressed in this study.

The objectives in this study are: (1) to investigate the genetic variability in the rate of wound healing in the genetically distantly related inbred strains of mice; (2) to determine from which progenitor strain the rapidwound-healing phenotype in MRL-F mice was derived; (3) to explore the mode of gene action using different genetic backgrounds; and (4) to estimate the broad-sense heritability of the rate of wound healing.

\section{Materials and methods}

\section{Animals}

Twenty inbred strains of mice (see Fig. 1 for the strains) were selected from a group of major inbred 

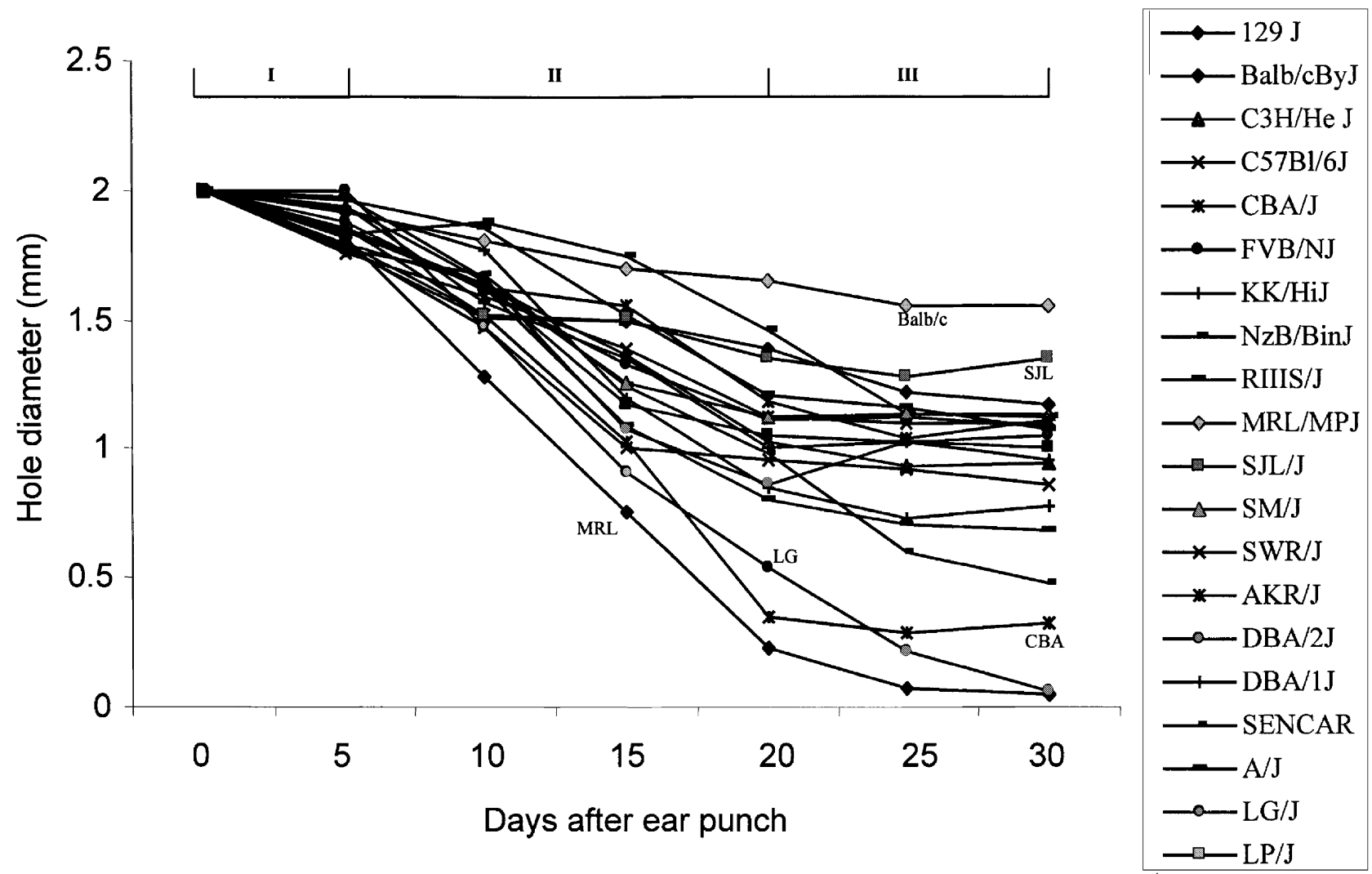

Fig. 1 Rates of healing of a 2-mm ear hole in 20 inbred strains of mice. The healing process can be divided into three phases on the basis of the rate of healing: initiation phase (I), rapid-healing phase (II), and slow-healing phase (III).

strains representing a diversified genetic origin. Three four-week old female mice for each strain were obtained from The Jackson Laboratories (Bar Harbor, ME) and housed at the Animal Research Facility, JL Pettis VA Medical Center, Loma Linda, CA, under the standard condition of $14 \mathrm{~h}$ light, $10 \mathrm{~h}$ darkness, ambient temperature of $20^{\circ} \mathrm{C}$, and relative humidity of $30-60 \%$. All $\mathrm{F}_{1}$ and $\mathrm{F}_{2}$ mice including $\left(\mathrm{MRL} / \mathrm{MpJ}-\mathrm{Fas}^{\mathrm{lpr}} \times \mathrm{LG} / \mathrm{J}\right)$ $\left(\mathrm{MRL} / \mathrm{MpJ}-\mathrm{Fas}^{\mathrm{lpr}} \times \mathrm{CBA} / \mathrm{J}\right)$, and $(\mathrm{MRL} / \mathrm{MpJ} \times \mathrm{SJL} / \mathrm{J})$ crosses were bred at the Animal Research Facility. The experimental protocols were in compliance with the animal welfare regulation and approved by the JL Pettis VA Medical Center, Loma Linda, CA.

\section{$M R L / M p J-F a s^{l p r}$ and MRL/MpJ strains}

MRL/MpJ-Fas ${ }^{\text {lpr }}$ mouse is a mutant derived from MRL/MpJ colony. The mutation is the direct result of a retrotransposon insertion into the second intron of the fas gene in the MRL/MpJ strain (Adachi et al., 1993). It has been shown that the mutation is not related to the rapid and complete wound closure in MRL mice (McBrearty et al., 1998). However, for an unidentified reason, MRL/MpJ-Fas ${ }^{\text {lpr }}$ mice have a slightly better healing capacity than MRL-MpJ mice (McBrearty et al., 1998 and our observation in this study).

\section{Ear punch and measurement}

A 2-mm through-and-through hole in diameter was made in the lower cartilaginous part of each ear using a metal ear punch (Fisher Scientific, Pittsburgh, Catalogue no. 01-337B) at 5 weeks of age for 20 inbred strains of mice and at 3 weeks of age for the parents, $F_{1}$ and $F_{2}$. The hole closure was measured using a $7 \times$ magnifier at days $0,5,10,15,20,25$ and 30 for 20 strains and at days $0,15,21$ and 25 for the crosses. Each hole was measured twice (horizontal and vertical measurement) from the back of the ear (less hair at the back) and the average value for each animal was calculated from four measurements of two ears and was used in the data analysis. The precision of hole measurement, determined by repeatedly measuring the same hole for 10 times, was $2.4 \%$ when the average size was $1.4 \mathrm{~mm}$ in diameter and $4.6 \%$ when the average size was $0.96 \mathrm{~mm}$ in diameter. 


\section{Statistical analysis}

ANOVA and cluster analysis were performed by using commercially available statistical software (STATISTICA, StatSoft, Tulsa, OK). The inbred strains of mice were clustered on the basis of the similarity of residual holesize at day 30 after ear punch.

Two methods were used for estimation of the genetic variance for wound healing. The first method involved data from the 20 inbred strains only. We used a one-way ANOVA with strains treated as groups. Three individuals were measured for wound healing within each inbred strain. The mean square within strains $\left(\mathrm{MS}_{\mathrm{W}}\right)$ reflects the environmental variance $\left(\sigma^{2}\right)$, while the mean square between strains $\left(\mathrm{MS}_{\mathrm{B}}\right)$ is determined by both the genetic variance between strains $\left(\sigma_{\mathrm{B}}^{2}\right)$ and the environmental variance. The expectations of $\mathrm{MS}_{\mathrm{W}}$ and $\mathrm{MS}_{\mathrm{B}}$ are $\mathrm{E}\left(\mathrm{MS}_{\mathrm{W}}\right)=\sigma_{\mathrm{W}}^{2}$ and $\mathrm{E}\left(\mathrm{MS}_{\mathrm{B}}\right)=\sigma_{\mathrm{W}}^{2}+\mathrm{r} \sigma_{\mathrm{B}}^{2}$, respectively, where $r=3$ is the replicate within each strain. Letting the expected mean squares equal the observed mean squares, we get the estimated broad-sense heritability:

$\hat{\mathrm{H}}^{2}=\frac{\hat{\sigma}_{\mathrm{B}}^{2}}{\hat{\sigma}_{\mathrm{B}}^{2}+\hat{\sigma}_{\mathrm{w}}^{2}}=\frac{\mathrm{MS}_{\mathrm{B}} \quad \mathrm{MS}_{\mathrm{w}}}{\mathrm{MS}_{\mathrm{B}}+(\mathrm{r} \quad 1) \mathrm{MS}_{\mathrm{w}}}$

The second method of estimation used the difference between variances of different populations. The $\mathrm{F}_{1}, \mathrm{P}_{1}$ and $\mathrm{P}_{2}$ are nonsegregating populations whose variances $\left(\mathrm{V}_{\mathrm{F}_{1}}, \mathrm{~V}_{\mathrm{P}_{1}}\right.$ and $\left.\mathrm{V}_{\mathrm{P}_{2}}\right)$ are purely due to environment. The $\mathrm{F}_{2}$, however, is a segregating population whose variance $\left(\mathrm{V}_{\mathrm{F}_{2}}\right)$ is determined by the sum of genotypic and environmental effects. Therefore, $\mathrm{V}_{\mathrm{F}_{2}}-\left(\frac{1}{2} \mathrm{~V}_{\mathrm{F}_{1}}+\frac{1}{4} \mathrm{~V}_{\mathrm{P}_{1}}+\right.$ $\frac{1}{4} \mathrm{~V}_{\mathrm{P}_{2}}$ ) is an estimate of the genotypic variance. The broad-sense heritability is then estimated from:

$\hat{\mathrm{H}}^{2}=\frac{\mathrm{V}_{\mathrm{F}_{2}} \quad\left(\frac{1}{2} \mathrm{~V}_{\mathrm{F}_{1}}+\frac{1}{4} \mathrm{~V}_{\mathrm{P}_{1}}+\frac{1}{4} \mathrm{~V}_{\mathrm{P}_{2}}\right)}{\mathrm{V}_{\mathrm{F}_{2}}}$

\section{Results}

\section{Genetic variability in the rate of wound healing among inbred strains}

The change in the hole diameter is the measurement of the rate of wound healing. Figure 1 shows the wound healing profiles for the 20 representative strains of mice. Each strain has a certain capacity for wound repair, but the rate of wound healing can be several-fold different. LG/J healed over $95 \%$ of the holes on the 30th day after wounding, in contrast to Balb/cByJ or $\mathrm{SJL} / \mathrm{J}$ that only healed less than $25 \%$ of the holes at the same period of time. The overall wound-healing profile revealed three healing phases: (a) an initiation phase

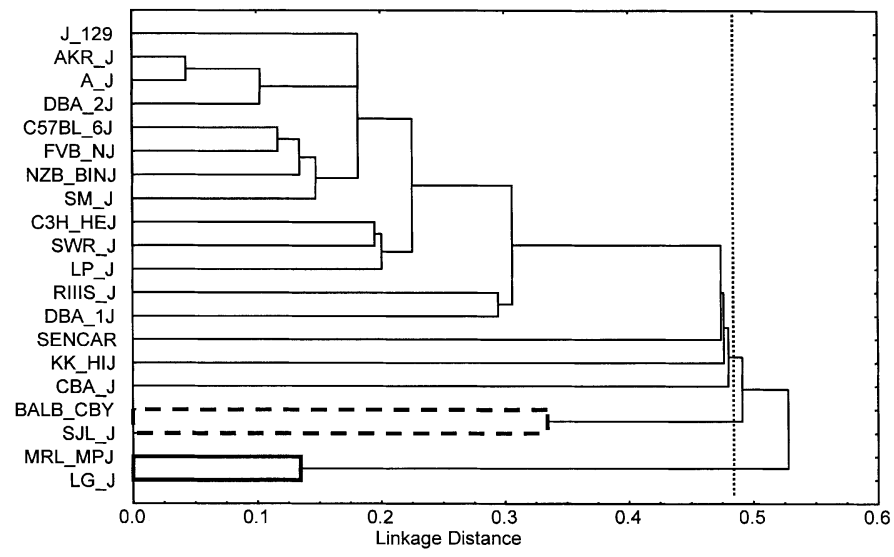

Fig. 2 Tree diagram for 20 inbred strains of mice. Cluster analysis was performed using the residual hole-size on the 30th day after ear punch. The $\mathrm{X}$-axis represents single linkage Euclidean distance. When the tree is divided into three groups (vertical dashed line), the fast and complete healers fell into one group indicated by the solid dark lines, the poor healers fell into another group indicated by dashed lines, and intermediate healers fell into the third group.

with an average healing rate of $0.028 \mathrm{~mm} /$ day (day 0 to day 5) where there was no significant difference in wound closure among all strains; (b) a fast-healing phase with an average healing rate of $0.085 \mathrm{~mm} /$ day (day 6 to day 20) where most of the strains achieved their maximal wound closure and exhibited markedly different healing capacity among strains; (c) a slowhealing phase with an average healing rate of $0.011 \mathrm{~mm} /$ day (day 21 to day 30) where most of strains had no healing or very little healing. On the basis of the similarity of residual hole size at day 30 after wounding, 20 strains were clustered into three groups (Fig. 2). Group 1 contained the fast healers, including MRL-F and LG/J mice. Strains in this group did not have an obvious slow-healing stage and closed the holes with a greater and more constant rate after initiation of healing. Group 2 included the intermediate healers that exhibited three distinct healing stages. Group 3 contained the poor healers, including Balb/cByJ and SJL/J. Strains in this group did not have an obvious fasthealing stage. On the average, fast healers $(0.1 \mathrm{~mm} /$ day $)$ healed twice as fast as intermediate healers $(0.05 \mathrm{~mm} /$ day) and four times as fast as slow healers $(0.02 \mathrm{~mm} /$ day) at the fast-healing stage.

\section{Genes regulating the rapid wound healing in MRL-F derived from $L G / J$ mice}

MRL-F mouse is a synthetic strain derived from the interbreeding of four progenitor inbred lines: $\mathrm{LG} / \mathrm{J}$ $\left.(75 \%), \quad \mathrm{AKR} / \mathrm{J} \quad(\mathrm{AKR}) \quad(12.6 \%), \quad \mathrm{C} 3 \mathrm{H} / \mathrm{He}^{\mathrm{J}}\right) \quad(\mathrm{C} 3 \mathrm{H})$ 


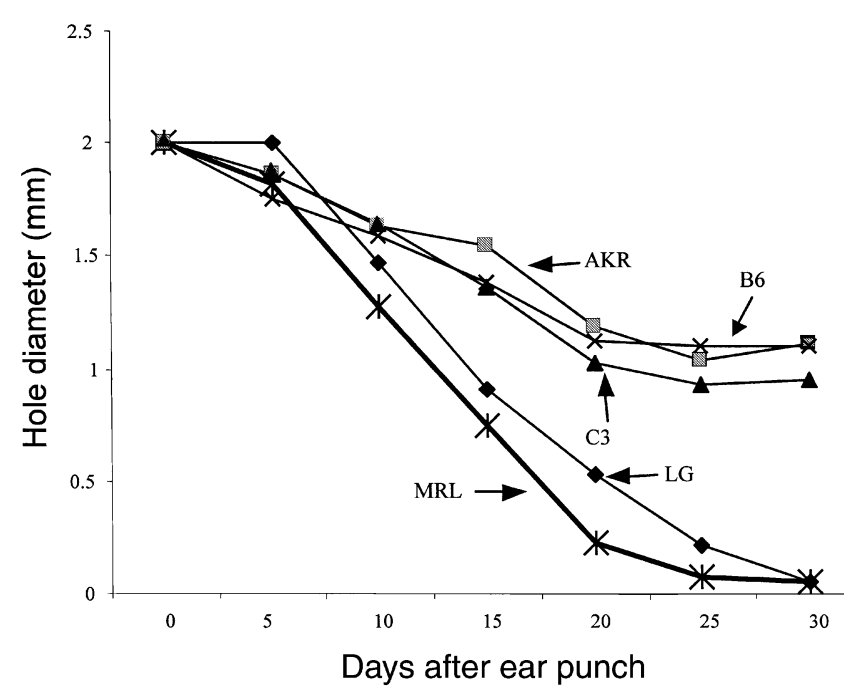

Fig. 3 The ear-healing profiles of MRL-F and its four progenitor strains over 30 days after wounding.

$(12.1 \%)$ and B6 $(0.3 \%)$. Figure 3 shows that LG/J completely healed the holes 30 days after wounding and had a similar healing rate to that of MRL-F, whereas the other three progenitor strains $(\mathrm{AKR}, \mathrm{C} 3 \mathrm{H}$, and B6) healed less or about $50 \%$ of the $2 \mathrm{~mm}$ hole. This result phenotypically suggests that the major fasthealer genes in MRL-F were probably derived from LG/J rather than from other progenitor strains. However, different sets of genes could code for a similar phenotype. In order to genetically clarify the issue, we examined the rate of healing in a (MRL-F $\times$ $\mathrm{LG} / \mathrm{J}) \mathrm{F}_{2}$ population. If the fast-healer genes in $\mathrm{LG} / \mathrm{J}$ were different from those in MRL-F (i.e. the fasthealer genes in MRL-F were largely derived from other progenitor strains), one would expect to observe a wide range of phenotypic variation with a normal distribution (under the assumption of additive gene effect) and some individuals that healed even faster than both parents due to transgressive segregation in the $\mathrm{F}_{2}$ population. Conversely, Fig. 4 shows that the ranges of healing rate in $F_{1}$ and $F_{2}$ mice were not significantly different from those of their parents, and super-healers were not identified when the observation was made on the 15 th day after wounding (data not shown). These results suggest that genes regulating the fast-healing phenotype in MRL-F mice were mainly derived from $\mathrm{LG} / \mathrm{J}$ mice.

\section{The modes of inheritance for the wound healing in segregating populations}

The genetic basis underlying the different rate of wound healing was analysed in two $F_{2}$ populations derived from crosses (MRL-MpJ $\times \mathrm{SJL} / \mathrm{J})$ and $(\mathrm{MRL}-\mathrm{F} \times$ $\mathrm{CBA} / \mathrm{J}$ ), respectively. Strain $\mathrm{SJL} / \mathrm{J}$ is a slow healer while $\mathrm{CBA} / \mathrm{J}$ is a relatively good healer with a unique healing profile (Fig. 1). In the $(\mathrm{MRL}-\mathrm{MpJ} \times \mathrm{SJL} / \mathrm{J})$ cross, the average residual hole size of $\mathrm{F}_{1}$ or $\mathrm{F}_{2}$ mice at day 21 after ear punch showed an intermediate value between the two parents (Fig. 5), and $F_{2}$ individuals exhibited a normal distribution, typical of a quantitative trait with additive gene effects (data not shown). However, the $(\mathrm{MRL}-\mathrm{F} \times \mathrm{CBA} / \mathrm{J})$ cross revealed a different healing profile, where the average residual hole size of $F_{1}$ mice had a healing capacity similar to one of their parents, CBA/J (Fig. 5) and that of the $\mathrm{F}_{2}$ offspring markedly deviated from normality, being shifted toward the average value of the CBA/J parent. When the $F_{2}$ mice were classified into the two groups on the basis of healing capacities in their parental strains (i.e. if the hole size was $\leq 0.3 \mathrm{~mm}$, the mice would be classified into the MRL-F group, whereas if the hole size was $>0.3 \mathrm{~mm}$, the mice would be
Fig. 4 The histogram of frequencies of residual hole size on the 21 st day after ear punch in parental $(\mathrm{MRL}-\mathrm{F} \times \mathrm{LG} / \mathrm{J}) \mathrm{F}_{1}$ and $F_{2}$ populations. The numbers of mice used for MRL-F, LG/J, $F_{1}$, and $F_{2}$ populations are $11,6,11$, and 65 , respectively.

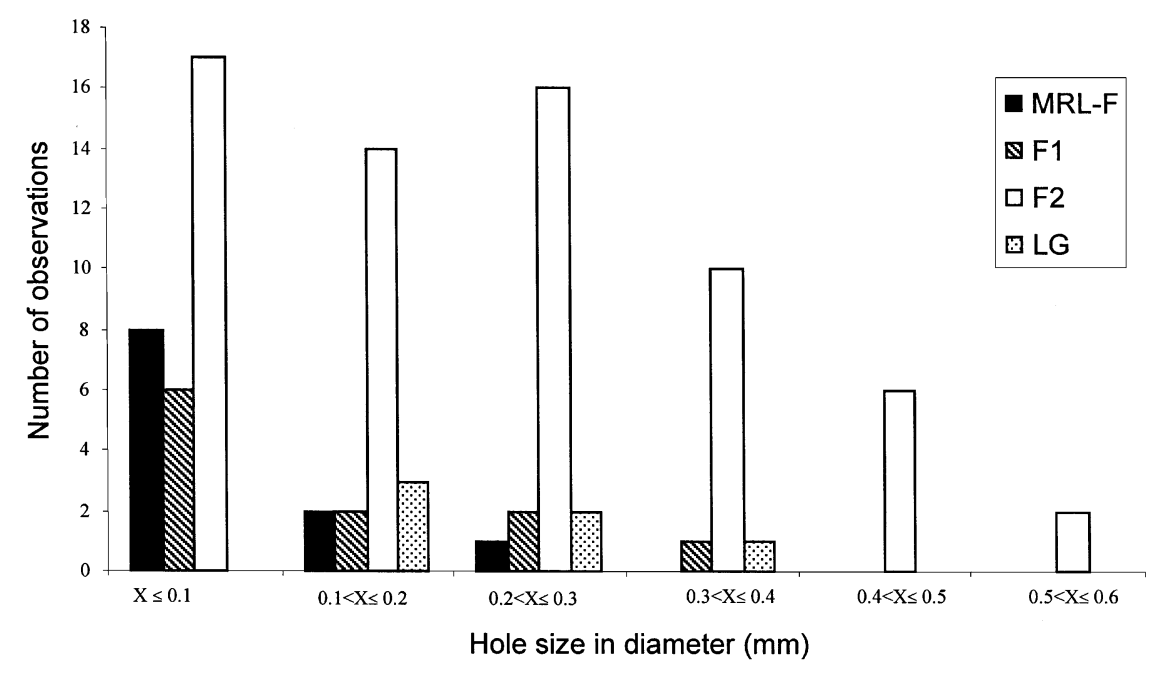

(C) The Genetics Society of Great Britain, Heredity, 86, 668-674. 


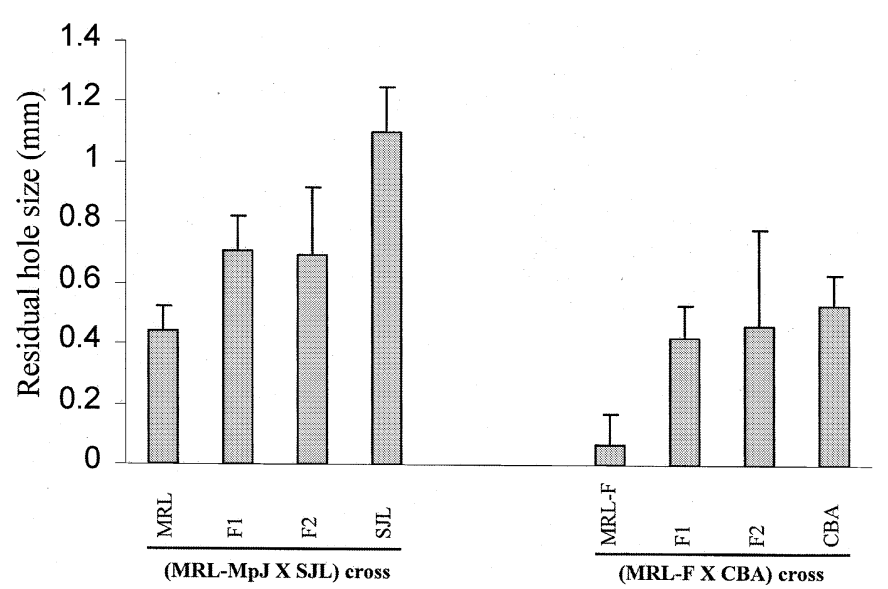

Fig. 5 The histogram of residual hole size on the 21st day after ear punch in parental, $F_{1}$ and $F_{2}$ populations, which shows that fast-healing genes in MRL-MpJ mice have additive effects in the $(\mathrm{MRL}-\mathrm{MpJ} \times \mathrm{SJL} / \mathrm{J})$ cross, and the repressor gene in CBA mice has a dominant effect in the $(\mathrm{MRL}-\mathrm{F} \times \mathrm{CBA} / \mathrm{J})$ cross. The numbers of mice used for the parental, $F_{1}$, and $F_{2}$ populations can be found in Table 1 .

classified into the CBA/J group), the ratio of segregation was 1:2.9, which is not significantly different from the expected ratio of $1: 3$ for the hypothesis of a single dominant gene action $\left(\chi^{2}=0.017,0.90<P<0.95\right)$. The average healing capacity of parental, $F_{1}$, and $F_{2}$ mice at days 15,21 , and 25 after wounding are summarized in Table 1, which shows similar healing profiles between different time points. These parentdependent offspring phenotypes demonstrate the inherited nature of wound healing.

\section{The rate of wound healing has a high broad-sense heritability}

Table 2 shows the estimated broad-sense heritability using variance of analysis of 20 strains. The average heritability of the three time points (15 days, 20 days, and 30 days after wounding) is 0.84 . When the segregating populations are used, the average estimated broadsense heritability (15 days, 21 days, and 25 days after wounding) is 0.88 from the cross (MRL-MpJ $\times \mathrm{SJL} / \mathrm{J}$ ) and 0.86 from the cross $(\mathrm{MRL}-\mathrm{F} \times \mathrm{CBA} / \mathrm{J})$, respectively (Table 3).

\section{Discussion}

We investigated the genetic variation for the rate of wound healing among 20 inbred strains of mice and explored the genetic basis underlying the difference using two segregating populations with different healing capacities. The salient findings of this study are: (1) the capacity for wound healing significantly differed among strains; (2) the fast-healer genes in MRL-F mice were most likely derived from the LG/J strain; (3) the fasthealer genes in the MRL-MpJ strain were additive in the $(\mathrm{MRL}-\mathrm{MpJ} \times \mathrm{SJL} / \mathrm{J})$ cross and the repressor gene in the $\mathrm{CBA} / \mathrm{J}$ strain was dominant in the $(\mathrm{MRL}-\mathrm{F} \times \mathrm{CBA} / \mathrm{J})$ cross; and (4) the healing rate had an estimated heritability of about 0.86 . We will sequentially discuss these findings below.

Ear punching has been traditionally used as a means of identification of mice kept in colonies. The rate of healing of this hole (normally $2 \mathrm{~mm}$ in diameter) has never been systematically studied among inbred strains. In this study, we found dramatic variation in the rate of healing among strains. The difference could be up to 4 times between a good healer $(\mathrm{LG} / \mathrm{J})$ and a poor healer (Balb/cByJ) at the fast healing stage. The healing capacity appears not related to their genealogies. Beck et al. (2000) has recently constructed a comprehensive genealogy chart of inbred mouse strains, which shows the origins and relationships of inbred mouse strains. In comparison with this chart, the hierarchical tree (Fig. 2), constructed on the basis of the residual hole size 30 days after ear punch, does not reflect the origins of these inbred strains. For example, CBA/J and Balb/cByJ are all derived from Caste's mice, but $\mathrm{CBA} / \mathrm{J}$ mice healed the holes five times faster than Balb/cByJ mice; B6 (C57related strains), FVB (Swiss mice) and NZB (Castle's mice) have different genealogical origins but have almost identical healing capacity.

The healing profile revealed three healing stages: initiation stage, fast-healing stage, and slow-healing stage. The difference in healing primarily occurred in the

Table 1 Measurement of average hole-size ( $\mathrm{mm}$ in diameter) at different time points after wounding in the parental, $\mathrm{F}_{1}$ and $F_{2}$ mice (mean $\pm \mathrm{SD}$ )

\begin{tabular}{|c|c|c|c|c|c|c|c|c|}
\hline & \multicolumn{4}{|c|}{$\mathrm{MRL}-\mathrm{MpJ} \times \mathrm{SJL} / \mathrm{J}$} & \multicolumn{4}{|c|}{$\mathrm{MRL}-\mathrm{F} \times \mathrm{CBA} / \mathrm{J}$} \\
\hline & MRL-MpJ & $\mathrm{SJL} / \mathrm{J}$ & $\mathrm{F}_{1}$ & $\mathrm{~F}_{2}$ & MRL-F & $\mathrm{CBA} / \mathrm{J}$ & $\mathrm{F}_{1}$ & $\mathrm{~F}_{2}$ \\
\hline No. of mice & 19 & 20 & 36 & 500 & 11 & 8 & 9 & 78 \\
\hline Day 15 & $0.70 \pm 0.10$ & $1.27 \pm 0.12$ & $0.97 \pm 0.09$ & $0.90 \pm 0.30$ & $0.42 \pm 0.06$ & $0.78 \pm 0.10$ & $\mathrm{~N} / \mathrm{A}$ & $0.72 \pm 0.20$ \\
\hline Day 21 & $0.44 \pm 0.10$ & $1.10 \pm 0.10$ & $0.71 \pm 0.11$ & $0.69 \pm 0.32$ & $0.07 \pm 0.08$ & $0.53 \pm 0.09$ & $0.42 \pm 0.05$ & $0.46 \pm 0.19$ \\
\hline Day 25 & $0.33 \pm 0.12$ & $1.01 \pm 0.10$ & $0.61 \pm 0.12$ & $0.60 \pm 0.32$ & $0.01 \pm 0.02$ & $0.46 \pm 0.09$ & $\mathrm{~N} / \mathrm{A}$ & $0.38 \pm 0.20$ \\
\hline
\end{tabular}


Table 2 Analysis of variance of the healing rate at different time points using 20 inbred strains of mice

\begin{tabular}{lccccccccc}
\hline Variable & SS effect & Df effect & MS effect & SS error & Df error & MS error & $F$ & $P$ & $h^{2}$ \\
\hline Day 15 & 3.78 & 19 & 0.199 & 0.929 & 40 & 0.023 & 8.57 & $>0.001$ & 0.72 \\
Day 20 & 6.92 & 19 & 0.364 & 0.418 & 40 & 0.01 & 34.8 & $>0.001$ & 0.92 \\
Day 30 & 9.13 & 19 & 0.481 & 0.857 & 40 & 0.021 & 22.4 & $>0.001$ & 0.88 \\
\hline
\end{tabular}

$h^{2}$, estimated broad-sense heritability; SS, sum of squares; Df, degrees of freedom; MS, mean squares.

Table 3 Estimated broad-sense heritabilities at different time points using variances of the parental, $F_{1}$ and $F_{2}$ populations of mice

\begin{tabular}{|c|c|c|c|c|c|c|c|c|c|c|}
\hline \multirow[b]{2}{*}{ Time } & \multicolumn{4}{|c|}{ Variance $(\mathrm{MRL}-\mathrm{MpJ} \times \mathrm{SJL} / \mathrm{J})$} & \multirow[b]{2}{*}{$h^{2}$} & \multicolumn{4}{|c|}{$\mathrm{F}$} & \multirow[b]{2}{*}{$h^{2}$} \\
\hline & MRL-MpJ & $\mathrm{SJL} / \mathrm{J}$ & $\mathrm{F}_{1}$ & $\mathrm{~F}_{2}$ & & MRL-F & $\mathrm{CBA} / \mathrm{J}$ & $\mathrm{F}_{1}$ & $\mathrm{~F}_{2}$ & \\
\hline Day 15 & 0.01 & 0.015 & 0.0085 & 0.0916 & 0.88 & 0.0039 & 0.01 & N/A & 0.0416 & $0.83 \dagger$ \\
\hline Day 21 & 0.01 & 0.009 & 0.0118 & 0.1014 & 0.89 & 0.0064 & 0.0073 & 0.0029 & 0.0366 & 0.87 \\
\hline Day 25 & 0.015 & 0.011 & 0.014 & 0.103 & 0.87 & 0.0004 & 0.0089 & $\mathrm{~N} / \mathrm{A}$ & 0.0408 & $0.89 \dagger$ \\
\hline
\end{tabular}

Estimated heritabilities are in bold.

$\dagger$ Environmental variances were estimated from the average of two parents.

fast-healing stage. The rate of healing at this stage is three times faster than that of initiation stage and eight times faster than that of slow-healing stage. The rate of fast healing and the time period of fast healing will determine overall healing performance. Therefore, elucidation of molecular mechanisms underlying the healing capacity should target the fast-healing stage.

The MRL-F mouse is the best healer among 20 strains studied. To investigate the potential origin of the fasthealer genes, we examined the healing capacity of four progenitor strains of MRL-F mice and determined that $\mathrm{LG} / \mathbf{J}$ is the most likely donor for the fast-healing phenotype of MRL-F. This conclusion is reinforced by overlapping phenotypic distribution in the parental $(\mathrm{MRL}-\mathrm{F} \times \mathrm{LG} / \mathrm{J}) \quad \mathrm{F}_{1}$ and $\mathrm{F}_{2}$ populations. The $\mathrm{LG} / \mathrm{J}$ mouse was developed by Goodale with selection for large body size (Chai, 1961). Fast-healing capacity in LG/J is unlikely to be associated with the body size, because SENCAR with a large body size $(39.6 \pm 3.9 \mathrm{~g})$ has an average healing rate whereas CBA/J, with a small body size $(24.6 \pm 1.2 \mathrm{~g})$, is a good healer. The coefficient of correlation between body weight and healing rate 30 days after wounding is $-0.26(P=0.191)$. It would be interesting to investigate where these fasthealer genes came from and how they were maintained during the selection of body size. There are two substrains, LG/J and LG/Ckc, which were separated at $\mathrm{F}_{27}$. Further examination of the healing capacity in the $\mathrm{LG} / \mathrm{Ckc}$ mice should provide insight into the evolutionary origin of these fast-healer genes.

To examine the mode of inheritance of these genes, two segregation populations were produced:
$(\mathrm{MRL}-\mathrm{MpJ} \times \mathrm{SJL} / \mathrm{J})$ and $(\mathrm{MRL}-\mathrm{F} \times \mathrm{CBA} / \mathrm{J})$. The rationale for selecting the $(\mathrm{MRL}-\mathrm{MpJ} \times \mathrm{SJL} / \mathrm{J})$ cross was based on their different phenotypes in the rate of ear healing. We did not select the MRL-F strain for this particular cross, which was used in the (MRL-F $\times \mathrm{CBA} /$ J) cross, because this cross will be used for bone density screening as well and MRL-F mice are highly susceptible to autoimmune disease and their health conditions will deteriorate with age, which will affect the measurement of bone density.

A normal distribution profile in the (MRL-MpJ $\times$ $\mathrm{SJL} / \mathrm{J}) \mathrm{F}_{2}$ mice indicates that the genes regulating fast healing have an additive effect and no major gene with dominant inheritance exists in this segregation population. We hypothesized that the (MRL-F $\times \mathrm{CBA} / \mathrm{J}) \mathrm{F}_{2}$ cross should produce superhealers that have the ability to heal the hole faster than MRL-F, because both strains are good healers and have a different genetic origin (Beck et al., 2000). Surprisingly, the healing capacity of $F_{1}$ individuals fell into the range of CBA/J mice and the $\mathrm{F}_{2}$ population fits the ratio of $3: 1(\mathrm{CBA} / \mathrm{J}$ type:MRL-F type), suggesting that a dominant repressor gene was present in $\mathrm{CBA} / \mathrm{J}$ mice, which suppressed the action of the additive fast-healer genes derived from MRL-F. Because CBA/J itself is a good healer, the repressor most likely works in conjunction with the fast-healer genes, i.e. the fast-healer genes still function but are limited to a certain degree due to the presence of the repressor.

Estimated heritabilities using variance of analysis and two segregating populations at different time points consistently show that the rate of healing is a highly inherited trait (average $h^{2}=86 \%$ ). This makes the 
identification and isolation of fast-healer genes feasible and the genetic manipulation of the wound healing process possible.

In conclusion, the rate of wound healing is a genetically controlled quantitative trait with a high broad-sense heritability. The fast-healer genes exhibited an additive effect and the repressor gene showed a dominant effect. The healing capacity was a function of the number of fast-healer genes in the absence of the repressor gene and became a simple Mendelian trait (independent of the number of the fast-healer genes) in the presence of the repressor gene.

\section{Acknowledgements}

This work was supported by Assistance Award No. DAMD17-99-1-9571. The U.S. Army Medical Research Acquisition Activity, 820 Chandler Street, Fort Detrick MD 21702-5014, is the awarding and administering acquisition office. The information contained in this publication does not necessarily reflect the position or the policy of the Government and no official endorsement should be inferred. The authors wish to thank the JL Pettis VA Medical Center for their administrative support and Miss Heather Davidson for her excellent technical support.

\section{References}

ADACHI, M., WATANABE-FUKUNAGA, R. AND NAGATA, S. 1993. Aberrant transcription caused by the insertion of an endogenous retrovirus in an apoptosis gene. Proc. Natl. Acad. Sci., 90, 1756-1760.
BECK, J. A., LLOYD, S., HAFEZPARAST, M., LENNON-PIERCE, M. $E T A L$. 2000. Genealogies of mouse inbred strains. Nat. Genet., 24, 23-25.

CHAI, C. K. 1961. Analysis of quantitative inheritance of body size in mice. IV An attempt to isolate polygenes. Genet. Res., 2, 25-32.

CHEN, E. A., ZHAO, L., BAMAT, M., VON BORSTEL, R. ET AL. 1999. Acceleration of wound healing with topically applied deoxyribonucleosides. Arch. Surg., 134, 520-525.

ClARK, L. D., ClARK, R. K. AND HEBER-KATZ, E. 1998. A new murine model for mammalian wound repair and regeneration. Clin. Immunol. Immunopathol., 88, 35-45.

Goss, R. J. 1992. The evolution of regeneration. Adaptive or inherent? J. Theor. Biol., 159, 241-260.

KUNimoto, в. T. 1999. Growth factors in wound healing: the next great innovation? Ostomy/Wound Management, 45, $56-64$.

MARTIN, P. 1997. Wound healing - aiming for perfect skin regeneration. Science, 276, 75-81.

MCBREARTY, B. A., ClARK, L. D., ZHANG, X. M., BLANKENHORN, E. P. $E T A L$. 1998. Genetic analysis of a mammalian woundhealing trait. Proc. Natl. Acad. Sci., 95, 11792-11797.

ROTHE, M. AND FALANGA, v. 1992. Growth factors and wound healing. Clinics Dermatol., 9, 553-559.

SHAH, M., FOREMAN, D. M. AND FERGUSON, M. W. J. 1995. Neutralisation of TGF- $\beta_{1}$ and TGF- $\beta_{2}$ or exogenous addition of TGF- $\beta_{3}$ to cutaneous rat wounds reduces scarring. J. Cell Sci., 108, 985-1002.

SINGER, A. J. AND ClARK, R. A. F. 1999. Cutaneous wound healing. New England J. Med., 341, 738-746.

TERKELSEN, L. H., ESKILD-JENSEN, A., KJELDSEN, H., BARKER, J. H. ET AL. 2000. Topical application of cod liver oil ointment accelerates wound healing: an experimental study in wounds in the ears of hairless mice. Scand. J. Plast. Reconstr. Surg. Hand Surg., 34, 15-20. 